\title{
Children with Speech Language and Communication Needs in England: Challenges for Practice
}

\author{
Julie Elizabeth Dockrell ${ }^{*}$, Peter Howell ${ }^{2}$, Diane Leung ${ }^{2}$ and Andrew J. B. Fugard ${ }^{3}$ \\ ${ }^{1}$ Psychology and Human Development, Institute of Education, University College London, London, United Kingdom, \\ ${ }^{2}$ Department of Psychology, Division of Psychology and Language Sciences, University College London, London, United \\ Kingdom, ${ }^{3}$ Educational Psychology, Department of Clinical Educational and Health Psychology, University College London, \\ London, United Kingdom
}

OPEN ACCESS

Edited by: Brahm Norwich, University of Exeter, United Kingdom

Reviewed by: Gregor Ross Maxwell, University of Tromsø, Norway Nina Klang,

Uppsala University, Sweden

${ }^{*}$ Correspondence: Julie Elizabeth Dockrell j.dockrel/@ucl.ac.uk

Specialty section: This article was submitted to Special Educational Needs, a section of the journal

Frontiers in Education

Received: 27 February 2017 Accepted: 26 June 2017

Published: 19 July 2017

Citation:

Dockrell JE, Howell P, Leung D and Fugard AJB (2017) Children with

Speech Language and Communication Needs in England:

Challenges for Practice.

Front. Educ. 2:35.

doi: 10.3389/feduc.2017.00035
Teachers and speech and language therapists (SLTS) share concern about children's speech, language, and communication needs (SLCNs) but they have different foci because of their professional roles. Contemporary research has identified the challenges to schools when meeting the needs of children with SLCN, highlighted terminological controversies, and has increased opportunities for professional development. The views of 170 Educationalists and SLT professionals in England about SLCN, and the children's associated needs were compared for similarities and differences in an online survey that employed both categorical responses and Likert scales. Comparisons were made between teacher and SLT groups and between SLTs working in schools and clinics. There were few significant differences between the views of SLTs in clinics and education. In contrast, there were often large and significant differences between teachers and SLTS. Education professionals were less familiar with terminology related to speech difficulties, did not discriminate between behaviors that might differentiate speech from language difficulties and varied in the ratings given about other associated difficulties. Additionally, education professionals showed awareness of academic and behavior difficulties associated with language difficulties and highlighted associated problems with reading and writing. SLTs felt confident in their understanding of the relevant terminology but there was less clarity in the features that discriminated speech from language difficulties. Both the Educationalists and SLTs valued additional training needs with over $50 \%$ of the Education staff reporting that they had no training in SLCN. The lack of clarity about the language markers of SLCN by teachers and the requests for tools to help in the identification of speech and language problems in school-age children are important areas to address. Both SLTs and Education staff emphasized the co-occurrence of difficulties with reading comprehension and written text production, highlighting the importance of profiling children's language learning needs rather than a reliance on diagnostic categories.

Keywords: speech and language therapists, educational support, policy and practice, schools, speech and language needs

\section{INTRODUCTION}

Many young children experience speech and language delays (Law et al., 2000; McLeod and McKinnon, 2007), and enter school with poor language skills (Norbury et al., 2016). Addressing children's speech, language, and communication needs (SLCN) requires the engagement of both education and health professionals (Pring et al., 2012) and is a topic of national concern within 
the UK (Communication Trust, 2017) and internationally (USA: Houdrow et al., 2014; Australia: National Childcare Accreditation Council, 2010). These two groups of professionals provide important, but different, perspectives about the children's needs. Yet, there is persistent evidence that these professionals have different understandings of who the children with SLCN are, priorities for intervention and appropriate models of service delivery to meet their needs (Dockrell et al., 2014; Glover et al., 2015). Despite a desire to collaborate to service these needs (Hartas, 2004), the lack of systematic criteria for specifying the children's SLCN, and the variety of terms used to describe these problems raises particular challenges (Bishop, 2014; Reilly et al., 2014). These challenges raise barriers to interprofessional collaboration and the development of appropriately targeted interventions (Hartas, 2004). A vital first step toward addressing these issues is to establish current understandings of both the speech and language and other associated difficulties experienced by the children [see Bishop et al. (2016) for an analysis of the views of researchers and speech and language therapists (SLTs)]. Achieving this objective entails examining both groups of professionals' perceptions. To our knowledge, no direct comparison has been made of the views of a large sample of practising Educational and SLT professionals working in mainstream settings concerning speech and language. Previous work has focused on one group of professionals (Sadler, 2005; Dockrell and Howell, 2015), small samples in local areas (Glover et al., 2015; teachers $n=14$, SLTs $n=6$ ), or in specialist settings (Hartas, 2004). Additionally, none of these studies differentiated speech from language difficulties.

In England, the 2001 Special Educational Needs' (SENs) Code of Practice included a category "Communication and Interaction" which was further subdivided into SLCN and Autism Spectrum Disorders (ASD) (Department of Education and Skills, 2001). SLCN specifically refers to children whose primary need is reflected in their oral language and excludes sensory impairment, cognition, ASD, or a specific learning difficulty. There is evidence, on the other hand, that SLTs use SLCN when referring to a broader group of children (Dockrell et al., 2014). This categorization of SENs was retained when the code was revised in 2015 at which time an emphasis was added requiring health, education, and care to work together to enhance joint outcomes (Department for Education, 2015). In England, more children have SLCN than any other type of SEN (Department for Education, 2015) which further highlights the need for effective collaboration and bespoke professional development and resources. Effective collaboration is supported by a consensus by the professionals (Education staff and SLTS) concerning whom the target population is and what their co-occurring needs might be.

Education staff play a key role in both identifying children with SLCN and in supporting these and other pupils' language development. The majority of children with SLCN are in mainstream schools and, for many, outside agencies are not involved in supporting them (McLeod and McKinnon, 2007; Dockrell et al., 2014). This situation applies even though Education practitioners report experiencing a number of challenges in meeting the needs of children with SLCN (Dockrell and Lindsay, 2001; Mroz and Hall, 2003; Marshall et al., 2002; Marshall and
Lewis, 2014), and of gaining a better understanding of speech and language development and of the difficulties that can ensue if language difficulties are not addressed (Antoniazzi et al., 2010; Snow, 2014).

A potential means of addressing these difficulties is an increased presence of SLTs working in mainstream school settings (Dockrell et al., 2014). Such changes could provide a basis for knowledge-exchange between professionals, but this still requires a shared understanding of terminology and the nature of children's needs (Prelock, 2000). Both Education staff and SLTs have requested increased training and knowledge-sharing, with an emphasis on changes in service delivery models (Glover et al., 2015). Despite the evidence that training education and SLT students together improves linguistic and curricular knowledge the impact of such training has not been reflected by instructional practice to date (Wilson et al., 2016). In addition, few practitioners have participated in joint training activities (Glover et al., 2015). An initial step toward developing effective practices is to identify how the two groups of practitioners currently conceptualize language learning difficulties, their ensuing impacts on children with SLCN, and any professional training needs.

Understanding language difficulties and the impact these might have requires an awareness of both the difficulties the children are likely to experience and an awareness of groups of children who might be at particular risk. Knowledge about both these aspects potentially supports the development of better services and enhances communication between professionals. There are, however, no unequivocal language behaviors that allow language problems to be identified in a reliable and valid way. Several early language behaviors have been proposed as markers of language disorders. For example, failure to produce sentences of three or more words at age 3, could serve as a marker of later problems (Diepeveen et al., 2016). However, debate continues concerning whether such markers can predict problems at school entry (Reilly et al., 2010). Recently, a meta-analysis of the diagnostic accuracy of three of these markers, verb tense, nonword repetition, and sentence repetition, concluded that these were at best suggestive of a language impairment (Pawlowska, 2014). Moreover, there has been little attention to indicators of speech and language difficulties with school-age children (ContiRamsden et al., 2001) and even less attention to indicators of the types of language behaviors that might be evident in classroom contexts. For example, while both the inability to follow verbal instructions and not seeming to listen when spoken to have been identified as markers of language problems (for example, https:// www.betterhealth.vic.gov.au/health/healthyliving/receptivelanguage-disorder) there is no empirical evidence that supports this. Furthermore, it is likely that these behaviors may be an indication of a wide range of developmental problems. Hence, it is not certain which language markers can be used to accurately identify children with language difficulties and by corollary there is a dearth of information about how teachers might detect language difficulties. It is currently not clear which, if any, features of language performance alert teachers to language difficulties and the extent to which SLTs view these as features of SLCN.

In contrast to the limited work examining language behavior in the classroom that might indicate that a child has a speech or 
language difficulty, there is a better understanding of the educational and social implications when such problems are present. However, the distinction between speech and language is rarely a focus in these contexts. Children with language difficulties tend to have poorer educational outcomes (Durkin et al., 2009) but data about children with speech problems is sparse. There is a high risk of difficulties in literacy for both groups (language: Snowling and Hayiou-Thomas, 2006; speech: Leitao and Fletcher, 2004). Numeracy (Cowan et al., 2005; Donlan et al., 2007). Also, difficulties in producing written text (Dockrell et al., 2009) have primarily been reported for children with language difficulties rather than speech problems. Problems with peer relations and self-esteem have been reported for children with language difficulties (Lindsay and Dockrell, 2000; Lindsay et al., 2010a; St Clair et al., 2011; Bakopoulou and Dockrell, 2016) and speech difficulties (Davis et al., 2002; Tudor et al., 2013). Whilst further comparative research is required, the current research evidence suggests that children with language difficulties have more pervasive problems associated with a range of educational and social processes than do children with speech problems alone.

These challenges are likely to impact directly on classroom activities and, potentially, on the ways in which professionals conceptualize children's needs. While there is some evidence that teachers are aware that language problems lead to literacy and behavior difficulties (Dockrell and Lindsay, 2001), practising SLT's understanding about these links is less apparent [see Wilson et al. (2016) for evidence of limited understanding about the relationship between language problems and these difficulties in trainee SLTs]. Moreover, there is currently little evidence concerning whether teachers and SLTs distinguish between the impacts of speech versus language difficulties in educational contexts.

Better understanding of population parameters enhances planning service provision and the identification of children's needs. SLCNs are more common in children who live in areas of social disadvantage (Korpilahti et al., 2016). There is also consistent evidence that children from lower socio-economic backgrounds (SES) are exposed to less high quality language both at home (for example, Vanormelingen and Gillis, 2016) and in school (Wright and Neuman, 2014) and that this leads to poorer vocabulary, grammar, and language processing (Schwab and Lew-Williams, 2016). Although disadvantaged populations in England receive greater levels of service from SLTs, there are still large inequalities in provision among socially deprived groups (Pring, 2016). Whether these inequalities in service provision arise because of limited resources or failing to be sensitive to the children's likely needs is not known.

The relationship between SLCN and ethnicity or race is lesswell researched but Strand and Lindsay (2009) reported that children of Chinese, Bangladeshi, Black African, Black Caribbean, and Black other backgrounds were over-represented in samples of children with SLCN. Similarly, children whose first language is not English [English as an additional language (EAL)] are overrepresented in samples of children with SLCN compared with monolingual English speakers (Dockrell et al., 2014). However, the disproportionate number of children with EAL who have SLCN in the community is not reflected in SLT service statistics
(Hambly et al., 2013). In sum certain population characteristics are associated with SLCN but there are disparities in their use as flags to provide additional services or monitor progress and in the extent to which different professional groups are alert to these disproportionalities.

To our knowledge, no attempt has been made to systematically examine the differences between the views of experienced Education and SLT professionals in a large sample working in mainstream settings about children with SLCN. This is of central importance to policy and practice in England, as in other countries, since the guidelines emphasize the importance of multiprofessional working (Department for Education, 2015, p. 24) yet there remain uncertainties about the specific target population. To address this gap, this study sought to elicit professional understandings of SLCN to inform research and practice using an online questionnaire. The main focus of the research was a comparison of the views of SLTs and Education professionals' understandings. To achieve this objective, the study focused on four major areas of which have been examined in the research literature: (1) understanding of terminology; (2) spoken language indicators of SLCN; (3) associated academic needs and behavioral challenges; and (4) barriers to meeting the children's needs.

We expected that Education staff would be less familiar than SLTs with current terminology surrounding different speech and language problems and would be less aware of different proposed language markers of SLCN. In contrast, we anticipated that Education staff would have better awareness of the range of educational and behavioral problems that are often experienced by the children with SLCN (Dockrell and Lindsay, 2001; Wilson et al., 2016) and a more nuanced understanding of their own specific training needs. We also expected SLTs to distinguish clearly between speech and language problems given their training, have a more nuanced understanding of the types of problems which occur with speech and language and clearly differentiate speech from language problems. We also predicted that SLTs working in schools (as opposed to clinics) would be more aware of the wider educational implications of experiencing an SLCN.

\section{MATERIALS AND METHODS}

\section{Respondents}

The online survey was accessed by 350 respondents in England. Two-hundred and four self-declared as Education professionals and 146 as SLTs. A significant proportion of respondents omitted sections which were intended for both groups and therefore precluded comparative analyses. To prevent response biases, all respondents with missing data for these items were removed from the sample, leaving 170 participants in the final survey sample (SLTs $n=67$; Education staff $n=103$ ). For those remaining in the sample, there were still within discipline questions where respondents did not give an answer, thus respondents were dropped from those analyses when answers were missing.

The majority of the respondents from the Education group were from Greater London (42.7\%), whereas the SLTs were 
predominantly from the North West (29.9\%) and the Midlands $(28.4 \%)$ and work location was typically urban (Education group, 66\%, SLT group 55.2\% see Tables S1 and S2 in Supplementary Material). ${ }^{1}$ Respondents were experienced practitioners as over $72 \%$ of the SLT group and $52 \%$ of the Education group had worked in their role for more than 5 years.

The two groups estimated the percentage of pupils that they worked with who had: special education needs (SEN); learned EAL; were eligible for the pupil premium; or who required support for SLCN. "Don't know" responses $(<5 \%)$ were removed and the remaining responses collapsed into " $<25 \%$," "between 26 and 75\%," and "more than 75\%" (Table S5 in Supplementary Material). There were significant associations between respondent group and: pupils with: $\operatorname{SEN}, \chi^{2}(2, n=169)=34.81, p<0.001$, $\Phi \mathrm{c}=0.45$; EAL, $\chi^{2}(2, n=166)=7.70, p=0.02, \Phi_{c}=0.22$, and SLCN, $\chi^{2}(2, n=170)=77.31, p<0.001, \Phi c=0.67$ working across a range of key stages (Table S4 in Supplementary Material). The SLTs reported working with more pupils with SEN and SLCN than the Education group whereas the Education respondents reported working with more pupils with EAL. There was no association for pupil premium $\left[\chi^{2}(2, n=141)=0.09\right.$, $\left.p=0.95, \Phi_{\mathrm{c}}=0.03\right]$.

The SLTs were initially divided into three subgroups based on where they worked: education; clinic; student. When aspects of the study focused on SLTs in practice, the student SLT subgroup was excluded. There were 48 SLTs in education and 17 SLTs in clinics. They reported similar locations of work, time in role, and work with pupil groups (see Tables S1-S3 in Supplementary Material). There were no significant associations between the SLT subgroups and number of pupils with SEN, EAL, pupil premium, and SLCN that they worked with (Tables S6 and S7 in Supplementary Material). Subsequent analyses compared responses from SLTs working in education and clinics. However, as there were no statistically significant differences on any measure the results are not presented here but are available from the authors.

Only respondents in Education settings were asked about their patterns of working with SLTs. Almost all (88.35\%) of the respondents in the Education group indicated that they had access to SLTs in their school where the modal frequency of visits by SLTs to schools was weekly (36.9\%, see Table S8 in Supplementary Material for details). Those with access to SLTs also reported that about a quarter $(25.2 \%)$ of the SLTs worked in classrooms.

\section{Procedure}

Education, SLT services, and training providers working for children with SLCN were contacted and asked to distribute the link to the survey. Participation was voluntary and responses were anonymized. The deadline for completion was indicated on the survey. Two reminders were sent before the survey was closed.

Email lists for both groups of professionals were used to identify and contact potential participants and the people contacted

${ }^{1}$ Full details of all responses are available in supplementary material and are indicated by SM and the relevant table number. were also asked to pass the link on to other appropriate parties. As participation was voluntary and the details of the distribution lists were confidential, there was no control over who completed the survey. However, all participants provided background information about their professional status. This included details about gender, years in post, contact time with children (only for SLTs), and school type. This provided indicative data of the representativeness of the sample.

Ethical agreement was provided for the study by the UCL, Institute of Education Research Ethics Committee, which adheres to the British Psychological Society guidelines.

\section{Survey}

The survey was based on a review of the research literature that related to SLCN, group interviews with Special Educational Needs coordinators (SENCos) ${ }^{2}$ and a pilot study with SENCos who were not respondents in the present study (see Dockrell and Howell, 2015). Items which were ambiguous or failed to discriminate across respondents in the pilot work were eliminated. Given that the aim was to compare teachers and SLTs, a preliminary version of the survey was given separately to a group of SLTs and experienced teachers. Amendments were made to clarify/edit questions and to modify response options, as appropriate, based on their advice. Cronbach's $\alpha s$, as indications of consistency of use of all scales, are reported in the results section. The majority of items required respondents to indicate their views on Likert scales.

The survey comprised five sections. ${ }^{3}$ Section 1 collected demographic data about training and working context as reported in the participants section. There were specific questions for Education staff about children in their classes and access to SLTs, and for SLTs about caseloads and work in schools. Section 2 examined barriers to successful working practices and training needs. Categorical responses were required. Nine items were identified as potential barriers to effective practice and are presented in Table 5. Training needs were examined with six items which asked information received and can be found in Table 6. Section 3 presented 14 terms used to refer to children with SLCN [see, for example, Bishop (2014)] and responses about familiarity were indicated. Items are presented in Table 1. Section 4 presented 11 oral language indicators of SLCN and are presented in Table 2. Respondents were asked to indicate whether these indicators were associated with speech only, language only, speech, and language difficulties or neither. Section 5 looked at the respondents' understandings of speech and language difficulties in terms of differential prevalence (SES, EAL, and ethnicity), additional educational needs $(n=4)$ and behavioral challenges $(n=9)$. Items were drawn from the research literature. See Tables $\mathbf{3}$ and $\mathbf{4}$ for educational needs and behavioral challenges.

The dependent variables were binary when categorical decisions about demographic information and the relationship between specific language behaviors and speech/language

${ }^{2}$ In England, an SENCo is responsible for the day-to-day operation of the school's SEN policy. All mainstream schools must appoint a teacher to be their SENCo.

${ }^{3}$ The full survey is available from the corresponding author. 
difficulties were collected. The remaining items required respondents to indicate their views on three-, four-, or five-point Likert scales.

\section{Statistical Analyses}

Our aim was to compare SLTs and Education staff with respect to understandings and working practice for children with SLCN. To address this objective, the primary data analyses compared responses between the two groups ( $\chi^{2}$ for categorical data, MANOVA for scaled responses) with group as the independent variable in all cases. In addition, patterns within groups were

TABLE 1 | Familiarity with speech, language, and communication needs (SLCN) terminology ( $M$ and SD) for the education and speech and language therapist groups. ${ }^{a}$

\begin{tabular}{llllll}
\hline & \multicolumn{2}{c}{$\begin{array}{c}\text { Education } \\
\text { group }(\boldsymbol{n}=\mathbf{1 0 3})\end{array}$} & & \multicolumn{2}{c}{$\begin{array}{c}\text { SLT group } \\
(\boldsymbol{n}=\mathbf{6 7})\end{array}$} \\
\cline { 2 - 3 } \cline { 5 - 6 } & $\mathbf{M}$ & SD & & $\mathbf{M}$ & SD \\
\hline SLCN & 3.64 & 0.56 & & 4.00 & 0.00 \\
Communication disorder & 3.23 & 0.77 & & 3.97 & 0.17 \\
Language difficulty & 3.32 & 0.74 & & 4.00 & 0.00 \\
Speech difficulty & 3.45 & 0.64 & & 4.00 & 0.00 \\
Specific language impairment & 3.27 & 0.76 & & 3.97 & 0.17 \\
Language learning difficulty & 2.87 & 0.98 & & 3.78 & 0.57 \\
Speech sound disorder & 3.02 & 0.97 & & 3.99 & 0.12 \\
Receptive language difficulties & 3.37 & 0.80 & & 4.00 & 0.00 \\
Expressive language difficulties & 3.38 & 0.77 & & 4.00 & 0.00 \\
Fluency difficulty & 3.10 & 0.89 & & 3.99 & 0.12 \\
Word finding difficulties & 3.20 & 0.93 & & 3.97 & 0.17 \\
Articulation disorder & 2.87 & 1.02 & & 3.96 & 0.37 \\
Phonological disorder & 3.03 & 0.91 & & 4.00 & 0.00 \\
Oro-motor dyspraxia & 2.42 & 1.12 & 3.93 & 0.26 \\
\hline
\end{tabular}

aScale ranged from 1 to 4 where 1 indicated that the respondent had "never heard of the term," to 4 "were familiar with the term and considered that they had a good understanding what the term means." analyzed using repeated-measures ANOVAs. Effect sizes are reported, all ANOVAs are reported after Greenhouse Geisser corrections, post hoc tests are computed using Bonferroni corrections. Effect sizes quantify the size of the difference between the two groups and by convention effect sizes above 0.80 are large, around 0.50 are medium, and below 0.20 are small.

To examine whether the two groups could be differentiated by their responses about the language behaviors, a recursive partitioning and regression tree analysis were conducted using the rpart package (Therneau et al., 2015) in R (R Core Team, 2017). This works by first finding the variable which best splits the data into the two groups, as achieved by minimizing generalized Gini impurity. The ideal value for this measure is 0 when all cases in a given group belong to one category, Education or SLT. The process is then repeated recursively on the resulting groups using remaining variables until no further splits can be made.

\section{RESULTS}

The results are presented in five sections reflecting the research questions.

\section{Familiarity with Terminology}

Respondents rated their familiarity with 14 terms used to refer to SLCNs (see Table 1 and Table S9 in Supplementary Material). Cronbach's $\alpha$ for the 14 terms was 0.96 . As expected, the responses given by the SLT group were virtually at ceiling consequently, analysis to compare respondent groups statistically to determine differences in familiarity with terms could not be performed for them.

However, familiarity differed significantly across the terms for the Education respondents $[F(8.26,842.55)=28.97, p<0.001$, $\eta 2=0.22]$; respondents were most familiar with $S L C N$ and least familiar with oro-motor dyspraxia $(p<0.05)$.

TABLE 2 | Percentage of respondents in the education and speech and language therapist (SLT) groups who reported difficulties which were either a feature of a speech difficulty, a language difficulty, both, neither or not sure. ${ }^{a}$

\begin{tabular}{|c|c|c|c|c|c|c|c|c|c|c|c|}
\hline \multirow[t]{2}{*}{ Difficulties with } & \multicolumn{2}{|c|}{ Speech } & \multicolumn{2}{|c|}{ Language } & \multicolumn{2}{|c|}{$\begin{array}{l}\text { Both speech and } \\
\text { language }\end{array}$} & \multicolumn{2}{|c|}{$\begin{array}{l}\text { Neither speech } \\
\text { nor language }\end{array}$} & \multicolumn{2}{|c|}{ Not sure } & \multirow[t]{2}{*}{$\chi^{2}(n=170)$} \\
\hline & Education & SLT & Education & SLT & Education & SLT & Education & SLT & Education & SLT & \\
\hline Stuttering/stammering & 76.7 & 44.8 & 0 & 4.5 & 16.5 & 29.9 & 2.9 & 19.4 & 3.9 & 1.5 & $26.90, p<0.001^{\star \star \star}$ \\
\hline $\begin{array}{l}\text { Inability to follow verbal } \\
\text { instructions }\end{array}$ & 0 & 0 & 84.5 & 100 & 12.6 & 0 & 2.9 & 0 & 0 & 0 & $11.49, p=0.003^{\star \star}$ \\
\hline Dysfluency & 35.0 & 38.8 & 10.5 & 6.0 & 30.1 & 34.3 & 1.9 & 19.4 & 22.3 & 1.5 & $27.93, p<0.001^{\text {***}}$ \\
\hline Errors in spoken grammar & 4.9 & 0 & 52.4 & 76.1 & 37.9 & 23.9 & 3.9 & 0 & 1.0 & 0 & $12.65, p=0.013^{\star}$ \\
\hline Errors in choice of words & 1.0 & 0 & 67.0 & 89.6 & 25.2 & 10.5 & 2.9 & 0 & 3.9 & 0 & $12.51, p=0.014^{\star}$ \\
\hline $\begin{array}{l}\text { Not seeming to listen when } \\
\text { spoken to }\end{array}$ & 0 & 0 & 45.6 & 71.6 & 26.2 & 6.0 & 18.5 & 14.9 & 9.7 & 7.5 & $14.56, p=0.002^{\star \star}$ \\
\hline Very talkative & 1.0 & 0 & 15.5 & 34.3 & 14.6 & 3.0 & 55.3 & 52.2 & 13.6 & 10.5 & $12.74, p=0.013^{\star}$ \\
\hline Circumlocutions & 7.8 & 3.0 & 18.5 & 77.6 & 9.7 & 17.9 & 3.9 & 1.5 & 60.2 & 0 & $78.83, p<0.001^{\text {*** }}$ \\
\hline Hesitations & 16.5 & 7.5 & 14.6 & 28.4 & 40.8 & 44.8 & 11.7 & 16.4 & 16.5 & 3.0 & $13.90, p=0.008^{*}$ \\
\hline Repeating words or phrases & 11.7 & 10.5 & 26.2 & 45.2 & 39.8 & 32.8 & 8.7 & 9.0 & 13.6 & 1.5 & $12.11, p=0.017^{\star}$ \\
\hline Selective mutism & 7.8 & 1.5 & 10.7 & 17.91 & 40.8 & 28.4 & 25.2 & 44.8 & 15.5 & 7.5 & $13.18, p=0.010^{\star}$ \\
\hline
\end{tabular}




\section{Differentiation of the Education and SLT Groups Based on Knowledge about Language Behaviors Indicative of SLCN}

Table 2 presents the ratings of the 11 types of language behavior that could indicate an SLCN. Respondents indicated whether each behavior was associated with: (1) speech difficulties, (2) language difficulties, (3) both, (4) neither types of difficulty, or (5) they were unsure. Cronbach's $\alpha$ across the 11 behaviors was 0.61 across all participants. Both Education and SLT respondents identified "inability to follow instructions" and "errors in word choice" as prevalent features of language difficulties. There was less consistency for speech difficulties, but over $75 \%$ of the Education staff indicated stuttering and stammering were features of speech difficulties. As Table 2 shows, all between group (Education and SLT) comparisons were significant.

The classification tree in Figure 1 depicts the pattern of answers about language behaviors that best differentiated between respondents from the two groups. The response options are designated S for speech difficulty, L for language difficulty, B for both speech and language difficulties, $\mathrm{N}$ for neither type of difficulty, and D for unsure (do not know). Each branch in Figure 1 lists the behavior and, after the equals sign, the responses (a selection from S, L, B, N, and D) given to that behavior which bifurcates the groups. The response options that are omitted for each behavior do not discriminate between the two groups.

The first behavior identified was circumlocution. This is consistent with the $\chi^{2}$ analysis shown in Table 2 in which circumlocution showed the biggest difference between groups (as indicated by the largest $\chi^{2}$ value and smallest $p$ ). Respondents who tended to use "not sure," "neither speech nor language difficulties," or "speech difficulties" for this behavior were likely to be from the Education group (oval box at left). In the case of this question, the Education group was unsure what type of difficulty circumlocution was as reflected in the response options that they employed.

Following the tree down, Educationalists used the "Both speech and language" response option for the behavior "not seeming to listen when spoken to". SLTs did not tend to use the "Speech" response option for "stuttering/stammering" and this path of the tree (including circumlocution and listening) characterized most members of the SLT group. Relatively smaller numbers of professionals were picked up by other patterns of response; see Figure 1. Looking across behaviors used in the classification tree, the "not sure" (D) response option was frequently given by the Education, but not the SLT, group (four of the seven behaviors). This provides further evidence that Education staff are not confident in their knowledge of speech and language difficulties. SLTs did not make a clear differentiation between problems reflecting language and those reflecting speech, perhaps reflecting the co-occurrence of speech and language difficulties but further raising questions about criteria used for differential diagnosis.

\section{Academic and Behavioral Difficulties Speech Difficulties}

Respondents used a five-point Likert scale (where 1 indicated that children with speech/language always experienced the

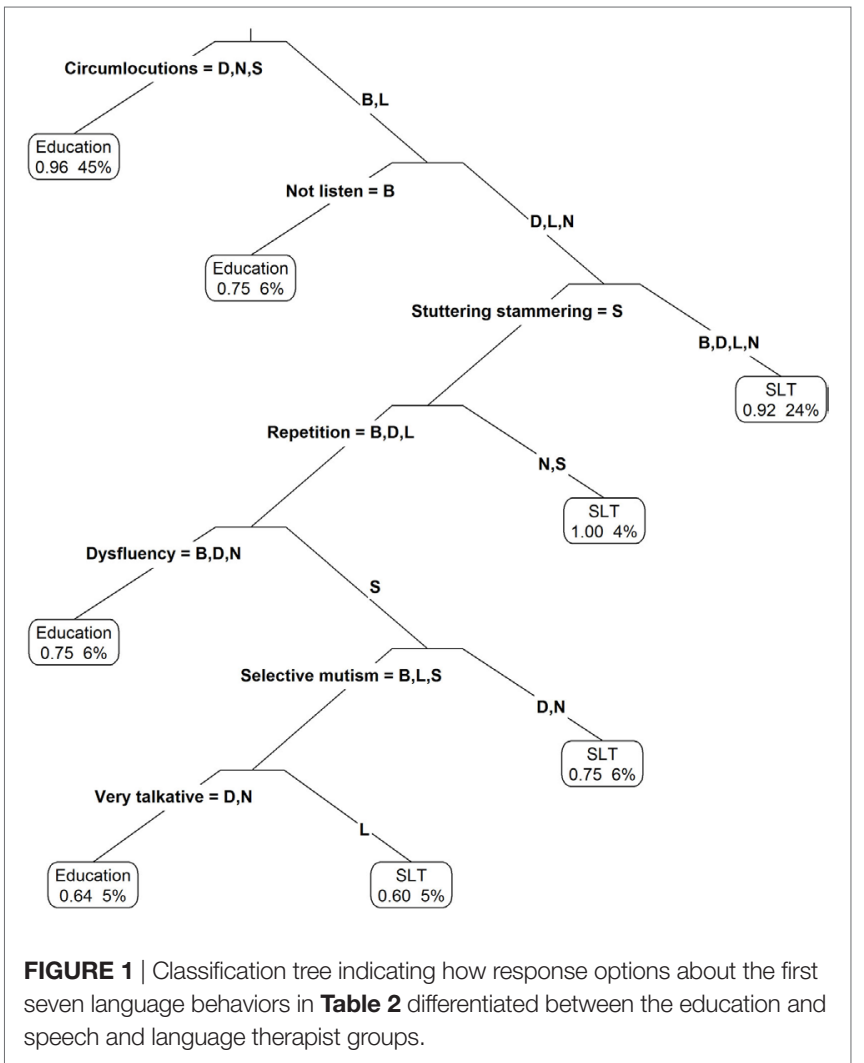

problem and 5 that children with speech/language problems never experienced the problem) to judge the frequency with which the 13 types of academic and behavioral difficulty were associated with speech difficulties. "Not sure" responses were omitted before analysis. The mean and SD of the responses for each type of difficulty are given in Table 3. Cronbach's $\alpha$ across the 13 features was 0.79 . Mean ratings in the following ranges were designated as "likely" (1-2.2), "moderately likely" (2.3-3.5), or "unlikely" (above 3.6) occurrences, respectively. The majority of behaviors were seen by both groups as moderately likely co-occurrences with speech difficulties.

We first examined the effect of group membership on respondents' views of educational and behavioral and social difficulties in children with speech problems using a MANOVA. Means (SDs) and statistical results are presented in Table 3. There was a significant difference with a small effect size for educational difficulties. There was a similar significant group effect with a small effect size for behavioral difficulties. In all cases, the Education group reported that difficulties with anxiety, depression, and selfesteem were more likely co-occurrences for children with speech problems than did the SLTs.

In a second step, within-group differences on their ratings were examined with a repeated-measures ANOVA. There was a within-group difference for educational difficulties in the Education respondents with a medium effect size $[F(2.519$, $\left.231.76)=12.62, p<0.001, \eta^{2}=0.42\right]$; "reading decoding" and "reading comprehension" differed significantly from "spelling" ( $p=0.006$ and $p<0.001$, respectively), where spelling was the 
TABLE 3 | Reported associated difficulties [M (SD)] for children with speech difficulties for education and speech and language therapist (SLT) groups. ${ }^{a}$

\begin{tabular}{|c|c|c|c|c|}
\hline & & $\begin{array}{c}\text { Education } \\
\text { group } \\
(n=93)\end{array}$ & $\begin{array}{l}\text { SLT group } \\
\quad(n=67)\end{array}$ & $\begin{array}{c}\text { Between } \\
\text { group effect }\end{array}$ \\
\hline & & M (SD) & M (SD) & \\
\hline \multirow[t]{5}{*}{$\begin{array}{l}\text { Academic } \\
\text { difficulties }\end{array}$} & & & & $\begin{array}{c}{[F(4,155)=10.92} \\
p<0.001\end{array}$ \\
\hline & $\begin{array}{l}\text { Reading } \\
\text { decoding }\end{array}$ & $2.54(0.68)$ & $2.36(0.52)$ & $p=0.04$ \\
\hline & $\begin{array}{l}\text { Reading } \\
\text { comprehension }\end{array}$ & $2.66(0.71)$ & $3.22(0.60)$ & $p<0.001$ \\
\hline & Spelling & $2.30(0.67)$ & $2.35(0.52)$ & \\
\hline & Writing texts & $2.38(0.65)$ & $2.60(0.56)$ & \\
\hline \multirow[t]{10}{*}{$\begin{array}{l}\text { Behavioral } \\
\text { difficulties }\end{array}$} & & & & $\begin{array}{c}{[F(9,128)=3.91} \\
p<0.001 \\
\text { Wilk's } \Lambda=0.78 \\
\left.\quad \eta^{2}=0.22\right]\end{array}$ \\
\hline & Being bullied & $2.68(0.67)$ & $2.80(0.59)$ & \\
\hline & $\begin{array}{l}\text { Bullying other } \\
\text { children }\end{array}$ & $3.23(0.66)$ & $3.38(0.62)$ & \\
\hline & $\begin{array}{l}\text { Behavior } \\
\text { difficulties }\end{array}$ & $2.75(0.59)$ & $2.89(0.50)$ & \\
\hline & Anxiety & $2.41(0.59)$ & $2.87(0.58)$ & $p<0.001$ \\
\hline & Depression & $2.91(0.66)$ & $3.16(0.69)$ & $p=0.03$ \\
\hline & $\begin{array}{l}\text { Interaction with } \\
\text { staff }\end{array}$ & $2.72(0.62)$ & $2.62(0.62)$ & \\
\hline & $\begin{array}{l}\text { Interaction with } \\
\text { peers }\end{array}$ & $2.52(0.57)$ & $2.49(0.60)$ & \\
\hline & Confidence & $2.18(0.57)$ & $2.44(0.57)$ & $p=0.02$ \\
\hline & Self-esteem & $2.13(0.59)$ & $2.45(0.57)$ & $p=0.003$ \\
\hline
\end{tabular}

${ }^{a}$ Participants rated behaviors on a five-point rating scale where 1 signified that a child with speech difficulties always experienced this problem, and 5 meant that the child never experienced this problem.

most commonly reported co-occurrence with speech difficulties for the Education respondents. "Reading comprehension" was a less likely reported co-occurrence than "writing texts" $(p<0.001)$. For the behavioral difficulties in children with speech difficulties, there was also a significant within-group difference for the Education respondents with a medium effect size $\left[F(5.179,424.65)=38.17, p<0.001, \eta^{2}=0.52\right]$; responses indicating "bullying other children" was a more unlikely cooccurrence of speech difficulties than all of the other behavioral difficulties $(p<0.01)$.

Similar repeated-measures ANOVAs were conducted with the SLT group for academic and behavioral difficulties. In both cases, large and significant differences were found [academic difficulties $F(2.030,134.01)=60.39, p<0.001, \eta^{2}=0.86$; behavioral difficulties $\left.F(4.414,238.35)=27.14, p<0.001, \eta^{2}=0.80\right]$. For academic difficulties, "reading comprehension" and "writing texts" were viewed as less likely co-occurrences than "reading decoding" and "spelling." For behavioral difficulties, similar to the findings with Education staff, responses indicating "bullying other children" was a more unlikely co-occurrence of speech
TABLE 4 | Reported associated problems [M (SD)] for children with language difficulties for education and speech and language therapist (SLT) groups.

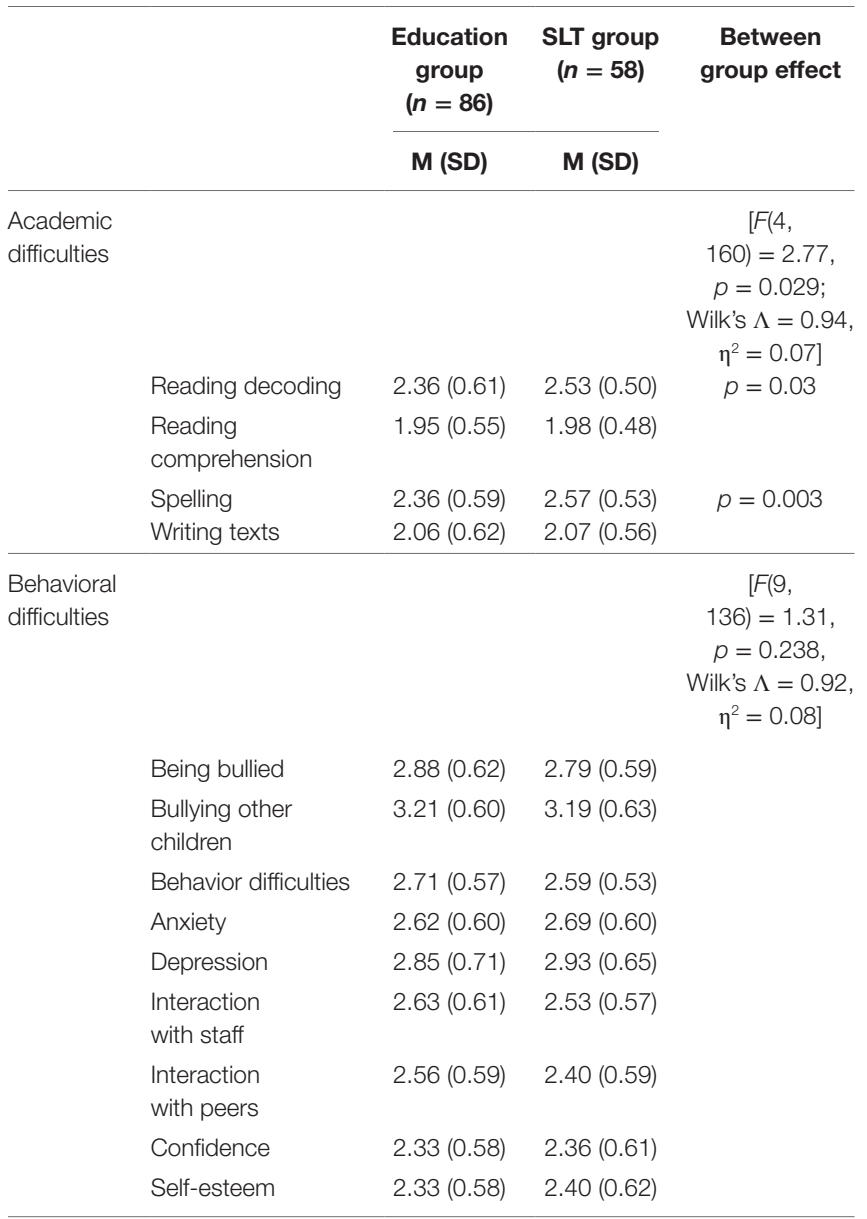

difficulties than all of the other behavioral difficulties $(p<0.001)$ apart from "depression" ( $p=0.975)$.

Although both SLTs and Education staff were aware of the impact of speech problems on learning and behavior, their emphasis was different. Teachers were more alert to the wider ramifications of speech problems both in terms of the curriculum and in terms of confidence and self-esteem. Overall both groups of respondents felt that difficulties were moderately likely to co-occur with speech problems but within-groups analyses demonstrated that the patterns of problems varied.

\section{Language Difficulties}

The 13 academic and behavioral difficulties were also judged for their association with language difficulties, Cronbach's $\alpha$ for the 13 behaviors was 0.85 . For language difficulties, both groups rated reading and writing difficulties as highly likely to co-occur. The mean and SD of the responses for each type of difficulty are given in Table 4. As with speech difficulties, we first examined between group differences and then within-group differences. Means (SDs) and statistical results are presented in Table 4.

There was a significant effect of group for educational difficulties for children with language difficulties, although the effect size was small. Responses differed for both "reading decoding" and 
"spelling" Education staff considered that these were more likely co-occurrences for children with language difficulties than did SLTs. There was no significant group effect for behavior problems.

There was also a within-group difference for the Education respondents for educational problems for children with language difficulties with a moderate effect size $[F(2.587,253.57)=22.79$, $\left.p<0.001, \eta^{2}=0.52\right]$. Both "reading comprehension" and "writing texts" were viewed as more likely co-occurrences with language difficulties than "reading decoding" and "spelling" $(p<0.001)$. There was also a large and significant within-group effect for behavioral difficulties $[F(4.704,409.256)=32.348, p<0.001$, $\left.\eta^{2}=0.80\right]$ where Education staff reported that "bullying other children" was the least likely co-occurrence with language difficulties (for all other behavior difficulties $p<0.001$ ).

Within-group analyses for the SLTs showed a large and significant difference for academic difficulties, $F(1.981,128.70)=44.08$, $p<0.001, \eta^{2}=0.80$ and behavioral difficulties, $F(5.035$, $286.98)=24.06, p<0.001, \eta^{2}=0.52$. A similar pattern to the Education respondents was evident where both "reading comprehension" and "writing texts" were rated as more common occurrences than, "reading decoding" and "spelling" for children with language difficulties $(p<0.001)$. For behavioral difficulties, "bullying other children" was significantly different from responses to all other behaviors $(p<0.01)$ except for "depression" $(p=0.07)$.

Both SLTs and Education staff were aware of the impact of language problems on learning and behavior. Overall, respondents felt that difficulties were highly likely to co-occur with language problems. For language problems, the two groups did not differ in their views of the likelihood of different patterns of behavior problems but there were significant differences in their views of academic difficulties where Education staff were more alert to reading decoding and spelling problems.

\section{Differential Occurrence of Speech and Language Difficulties}

Respondents assessed whether language and speech difficulties were more frequent for children from areas of social disadvantage, who spoke EAL or who had other SEN. "Don't know" responses were excluded before analyses were conducted. The majority of respondents from the Education and SLT groups reported that language difficulties were more common in children from areas of social disadvantage ( 90.4 and $98.5 \%$, respectively) and for children with SEN (93.8\%; 98.5\%). However, neither group considered that language difficulties were encountered more frequently when children spoke EAL (36.3\%; 21.3\%) (see Table S10 in Supplementary Material). There were associations between respondent group and responses for children with social disadvantage $\left[\chi^{2}(1, n=159)=4.21, p=0.040, \Phi \mathrm{c}=0.16\right]$ and EAL $\left[\chi^{2}(1, n=152)=3.87, p=0.049, \Phi c=0.16\right]$. SLTs were more likely to associate language difficulties with social disadvantage and Education respondents with EAL. There was no difference between groups for SEN $\left[\chi^{2}(1, n=164)=2.14\right.$, $p=0.144, \Phi c=0.14]$.

There were significant differences in the reported likelihood of speech difficulties for children with EAL [Education, 25.8\%; SLT, $\left.3.2 \%: \chi^{2}(1, n=151)=13.53, p<0.001, \Phi \mathrm{c}=0.30\right]$; but not for social disadvantage [Education, 69.3\%; SLT, 61.9\%: $\chi^{2}(1, n=151)=0.90, p=0.342, \Phi \mathrm{c}=0.08$ ]; or SEN [Education, 72.9\%; SLT, 73.9\%: $\left.\chi^{2}(1, n=161)=0.02, p=0.896, \Phi c=0.01\right]$. Details can be found in Tables S10 and S11 in Supplementary Material.

\section{Barriers to Meeting Needs}

To identify barriers to meeting the children's needs, we considered previous training and professional development, respondents' confidence, and resource needs. Mean responses and percentage responses to barriers are reported in Table 5. Responses that indicated that the topic was "not applicable" were removed before analysis $(<5 \%)$. For both the Education and SLT groups, the biggest barrier was lack of training in relevant areas.

For the Education group, there was a significant difference in ratings across response in a repeated-measures ANOVA $[F(4.856,451.59)=11.51, p<0.001]$. Responses to "lack of training in relevant areas" had the highest mean and all the comparisons between this option and the rest were significant $(p<0.01)$ apart from the comparison with "difficulties in knowing how to support children with SLCN." SLT responses also

TABLE 5 | Barriers to practice $[\%(n)]$ for Education $(n=94)$ and speech and language therapists (SLTS) $(n=62)$.

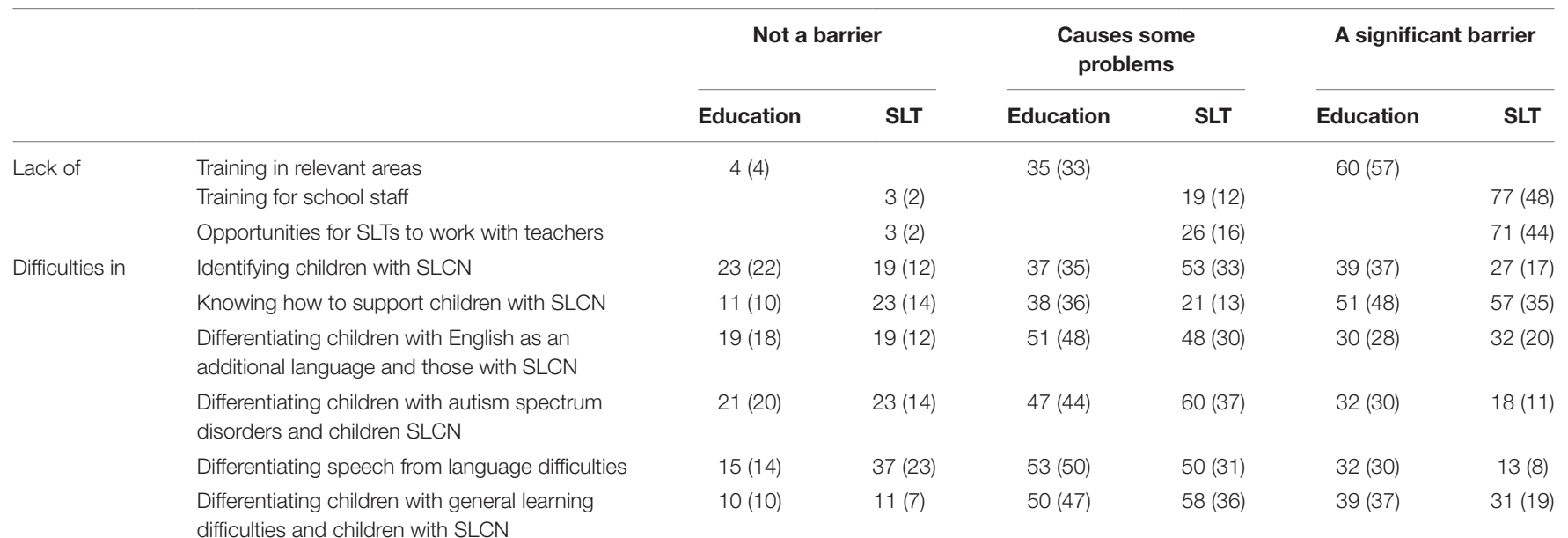


differed significantly across options $[F(4.864,296.69)=25.97$, $p<0.001]$. Responses to the "lack of training in relevant areas" option had the highest mean and were significant in all comparisons $(p<0.01)$ except for "difficulties in identifying children with SLCN."

Six questions related to initial training and specific guidance for children with SLCN were addressed to the Education group only (Table 6). More than half of the respondents reported that they had not received any of the forms of guidance for SLCN during their professional training.

The Education group was asked how confident they were about dealing with children with speech and language difficulties using a five-point scale ( 1 was entirely confident and 5 was not at all confident). The six items were: children with language difficulties; children with speech difficulties; professional support for children with language difficulties; professional support for children with speech difficulties; resources to support children with language difficulties; and resources to support children with speech difficulties. Mean responses to all six events were below 3 showing some confidence about access to resources in relation to children with SLCN but confidence varied significantly across options $[F(3.571,349.94)=5.42, p=0.001]$. Confidence about identifying resources to support children with speech difficulties was significantly lower than confidence about professional support for children with language difficulties $(p=0.001)$, professional support for children with speech difficulties $(p=0.006)$ and resources to support children with language difficulties $(p=0.004)$.

Respondents were asked how helpful specific resources were for supporting children with SLCN. They were most positive about receiving specific guidance $(82 \%)$ and least positive about receiving information about a diagnosis (52\%).

All respondents were asked whether a tool for identifying children with language difficulties would be useful. There were significant differences between response and respondent group, $\chi^{2}(4, n=165)=47.86, p<0.001$, with a large effect size, $\Phi c=0.54$. Details are given in Table S12 in Supplementary Material. A similar analysis to establish the usefulness of a tool for

TABLE 6 | Percentage of respondents in the Education group reporting information and guidance received during their professional training.

\begin{tabular}{llccc}
\hline & Not received & Received & Not sure \\
\hline $\begin{array}{l}\text { Information } \\
\text { about }\end{array}$ & $\begin{array}{l}\text { Children with } \\
\text { speech difficulties } \\
\text { Children with }\end{array}$ & 66 & 27 & 7 \\
language difficulties on & $\begin{array}{l}\text { How to support } \\
\text { children with }\end{array}$ & 67 & 23 & 10 \\
$\begin{array}{l}\text { speech difficulties } \\
\text { How to support } \\
\text { children with } \\
\text { language difficulties }\end{array}$ & 63 & 27 & 10 \\
$\begin{array}{l}\text { Resources for } \\
\text { children with } \\
\text { speech difficulties } \\
\text { Resources for } \\
\text { children with } \\
\text { language difficulties }\end{array}$ & 68 & 20 & 12
\end{tabular}

identifying children with speech difficulties also showed a significant association between the factors of group and useful/not useful, $\chi^{2}(4, n=165)=49.64, p<0.001$, with a large effect size, $\Phi_{c}=0.55$. In both cases, the Education group considered that such tools would be more useful than did the SLT group.

\section{Summary of Results}

Experienced practitioners responded to the survey, moreover the majority of the respondents from the Education group had experience of SLTs working in their schools. We established that the groups differed in the language behaviors that they reported indicated a speech or language difficulty, with Education practitioners expressing less certainty of what language behaviors are indicative of an SLCN. As a whole, language difficulties were reported to have more serious repercussions for academic problems and social/emotional problems than speech problems. However, the patterns of severity of impact varied for both the Education and SLT groups. Education practitioners reported a greater awareness of the emotional difficulties experienced by children with speech problems. Both groups highlighted lack of training as a significant barrier to meeting the children's needs, a finding consistent with the Education respondents' reports of their lack of training about SLCN. The results indicated that identifying resources to help children with speech difficulties was a particular area of concern for the Education group. Moreover, the Education respondents, but not the SLTS emphasized the need for tools to support them in the identification of children with speech and language difficulties.

\section{DISCUSSION}

To address the limited information available about the differences and similarities in the understanding of SLTs and Educational practitioners about SLCN, we administered a bespoke questionnaire which captured understandings of terminology, spoken language indicators of SLCN, associated academic needs, behavioral challenges, and professional barriers to meeting the children's needs. We had predicted that SLTs working in education, as opposed to clinics, would be more aware of the educational difficulties experienced by children with SLCN. We found no significant differences between the two groups of SLTS on any measure. In contrast, as predicted Education staff were less familiar than SLTs with current terminology surrounding different speech and language problems and were less aware of different proposed language markers of SLCN. The lack of familiarity with terminology related to speech difficulties by Education respondents is an unexpected and, to our knowledge, unreported finding. It was also anticipated that Education staff would have a better awareness of the range of educational and behavioral problems that are often experienced by the children with SLCN. The results did not conform this prediction and demonstrated a more nuanced situation that varied between speech and language and academic and behavioral challenges. Despite raised concerns about language difficulties no more than one-third of the Education respondents had received guidance or training in relation to SLCN and the both groups differed in 
the ways to address this gap. Education respondents rated the availability of tools to identify speech and language difficulties highly, whereas SLTS did not. In the subsequent discussion, each of the areas investigated is examined drawing implications for research and service development.

\section{Terminology}

As predicted, the Education respondents were less familiar with terms used to denote language and speech difficulties. Confidence was highest for the generic term SLCN, which reflects current categorization within the education special needs legislation (Dockrell et al., 2014), but not terminology used by SLTS nor the proposed changes to terminology (Bishop et al., 2017). SLTs consistently use SLCN to refer to a much broader groups of children. Given that a high proportion of Education staff indicated that they lacked a clear understanding of the terms used by SLTs and researchers, despite having regular contact with SLTs, this raises the question of how best to conceptualize a child's difficulties within an educational contexts. While the introduction of more standard, but still controversial, terminology (Bishop et al., 2017) may go some way toward reducing communication difficulties, it is likely that a different approach to working within education sectors is warranted and the current notion of providing a diagnosis may be unhelpful. Indeed given the constellation of language and speech difficulties a child may have and the lack of clarity for accurate diagnosis (Pawlowska, 2014) profiling children's strengths and needs within the spectrum of language and communication may be most helpful for practice and provide a better conceptualization. In relation to this, Education staff (76\%) reported that description of the child's difficulties was very important and significantly more useful than a formal diagnosis. Moving toward profiling children's language learning needs for practitioners' use may provide a firmer basis for supporting teaching and learning and monitoring progress, and is consistent with understandings of developmental trajectories (Mashburn and Myers, 2010).

Although the SLTs responses were at ceiling for their reported knowledge of the terms, the classification tree analysis of language indicators of SLCN reported by the SLTs and Education respondents provided a different picture. The procedure identified systematic differences in responses that differentiated the groups For example, the Education group considered Stuttering/ stammering to be a pure speech problem but the SLTs did not. Moreover, the Education respondents, but not the SLTs, classified stuttering, repetition, and dysfluency together as a speech problem. In contrast while very talkative was not considered a speech or language problem for the Education group it was for the SLTS. The extent to which these conceptual differences are important for policy and practice is likely to depend on the designated role of the professionals in the multidisciplinary team and speaks to the important role of the SLT in refining understanding of language processes in education (Glover et al., 2015) and considering which aspects of speech and language can be captured in the classroom context (Snow, 2014). These differences may go some way in explaining the identification of SLCN in educational settings (Norbury et al., 2016).

\section{Indicators of an SLCN}

We considered three dimensions which might indicate that a child was at risk of experiencing a speech/language difficulty: socio demographic factors, language behaviors, and other associated academic and behavioral needs. An understanding of these factors has implications for both the development of service delivery models and monitoring and intervention (Ebbels et al., 2017). Both groups of respondents were aware of the elevated occurrence of language difficulties in children from areas of disadvantage and for those children with SEN (Korpilahti et al., 2016). These results suggest that inequalities in service provision are a result of limited resources and not failing to be sensitive to children's needs (Pring, 2016). They do highlight the importance of developing models of service provision that address disproportionalities.

In contrast, the Education group were more likely to report that both speech and language difficulties were common in children with EAL than SLTs, with only 3\% of the SLTs reporting that speech difficulties were more common in children with EAL. Reduced numbers of children with EAL with speech sound disorder are indeed reported on the caseloads of SLTs (Skahan et al., 2007), despite the increasing evidence that children with EAL may be at specific risk of experiencing speech difficulties (Howell et al., 2016). The greater awareness of the educators might reflect their greater likelihood of encountering children from multilingual and bilingual backgrounds. In contrast, SLTs may be less likely to identify children who are not fluent speakers of English given the comparative lack of tools available to do this (Dockrell and Marshall, 2015) leading to a tendency to encounter more bilingual children who are competent in both languages. Bilingualism can confer language advantages and precocious language abilities have been reported to be associated with, for example, stuttering (Reilly et al., 2009). This would lead to different impressions about how EAL status affects SLCN across the two groups but suggests that more strategic attempts are needed to develop collaboration and exchanges between the two professional groups and the evaluation of collaborative training (Wilson et al., 2016).

Confidence in knowing what types of language behaviors were indicative of either speech or language difficulties was, as expected, lower for the Education group. Moreover, for the Education respondents none of the oral language behaviors presented distinguished speech from language difficulties. Education respondents were more likely to focus on general features of communication such as "not listening" or "dysfluency" or indeed reporting that they were "not sure." These behaviors are unlikely to discriminate children, difficult to identify reliably and raise challenges for appropriate support and intervention in educational contexts (Lindsay et al., 2010b; Norbury et al., 2016). To our knowledge, this is a novel finding and raises the question about which language behaviors Education staff should be alert to in classrooms [see Gracia et al. (2015) for a recent attempt to develop such a tool in Spanish]. That teachers have no readily available ways of capturing language problems is problematic given the likely under identification of children's language learning needs (Norbury et al., 2016). 
Even for the SLT respondents there was considerable variability in their views about which oral language features indicated a speech as opposed to a language difficulty. This is unexpected given attempts to identify distinct aspects of language, speech, or processing which characterize such problems (Bishop et al., 2016). While there was unanimity that "inability to follow verbal instructions" was an indicator of a language difficulty and over $85 \%$ agreement that errors in word choice were indicators of a language difficulty there was less consistency about other language behaviors. Over $15 \%$ of the SLTs reported that hesitations, "repeating words or phrases" dysfluency and "stuttering and stammering" were neither features of speech nor language difficulties, despite research evidence to the contrary (e.g., Boscolo et al., 2002).

Both groups of respondents reported on the associated literacy and behavioral challenges for children with speech or language difficulties, however their emphasis was different. Of particular note was the education respondents, but not the SLTs, awareness of mental health challenges for children with speech difficulties. Indeed communication difficulties are a risk factors for mental health difficulties and good communication skills have been identified as supporting mental health resilience (Public Health England, 2016). In our sample, these problems included problems with both confidence and self-esteem. Given the importance of social emotional and mental health factors for supporting the adjustment of children the teachers' insights point to an important gap in current support services for children with speech difficulties. Again these data support the importance of developing service delivery models that are premised on collaboration so as to deliver effective practice to meet all the needs of the child with an SLCN.

When children with language difficulties were considered, academic difficulties were reported to be a frequent co-occurrence with both groups reporting reading comprehension and writing as the most likely problems. The likelihood of behavioral problems was judged as moderately high by both groups and there were no significant differences in patterns of responding with "bullying other children" again being the least likely reported behavior. This is consistent with current research evidence which suggests that between 40 and $60 \%$ of children who experience language difficulties have behavioral challenges. However, to date there is inconsistent evidence that this is explained by their level of language difficulty, suggesting that other external (McIntosh et al., 2013) and within child factors may drive this relationship. Recently, van den Bedem and colleagues (under review) have argued that this reflects difficulties with understanding emotions rather than understanding language.

The similarities and differences between the groups when identifying co-occurring problems have implications for training and research. In terms of children with language difficulties, both groups highlighted co-occurrence of reading comprehension problems (Nation et al., 2004) and written text production (Mackie et al., 2013). Both of these are areas where further research could enhance identification and interventions and both skills have significant implications for future academic achievements. Research needs to address the extent to which it is the child's language difficulties per se, or their literacy difficulties which impact on later attainments (Conti-Ramsden et al., 2009; Dockrell et al., 2011).

The different patterns of problems highlighted likely reflect the contexts in which the professionals work. Teachers are more likely to regularly evaluate children's writing and have more opportunities to witness issues related to self-esteem and confidence. Alerting teachers to the fact that difficulties in these areas may reflect underlying language problems may mitigate the absence of reliable oral language indicators of language problems in the classroom. The exchange of information between professionals offers the possibility of a more comprehensive profile of the children's needs (Dockrell and Lindsay, 2001). The emphasis on literacy is also consistent with DSM-5 (APA, 2013) where language disorders include "persistent difficulties in the acquisition and use of language across modalities (i.e., spoken, written, sign language, or other) due to deficits in comprehension or production" and language abilities that are "substantially and quantifiably" below age expectations. Allowing for a broader reflection of language disorders would allow both teachers and therapists a wider frame of reference and, potentially, allow for more accurate identification of interventions. At minimum, the views of the staff from education point to a wider profiling of children's language learning needs.

\section{Barriers to Practice}

The major barrier to practice identified was the lack of training of Education staff and this is reflected by the difficulties Education staff experienced with terminology and oral language markers of SLCN but, also likely reflects different expectations about collaborative practice (McCartney, 1999; Baxter et al., 2009). Unexpectedly, $57 \%$ of the SLTs indicated that knowing how to support children with SLCN in the classroom was a major barrier and $27 \%$ highlighted challenges in identifying children with SLCN raising challenges for current models of SLT working practices [see, for example, Ebbels et al. (2017)]. For SLTs, there is a wide range of measures available to assess children's speech and language skills and the challenges probably reflect the different criteria in use and change in resources that have had an impact on professional roles with respect to SLCN (Lindsay et al., 2002). Different criteria are used even within the single professional groups. For example, DSM-5 includes monosyllabic whole-word repetitions as symptoms of stuttering, whereas the most widely used standardized instrument does not (Riley, 2009). In contrast, there are few measures that Education practitioners might use to identify SLCN and those that are commonly available capture language skills in younger children up to the age of 6 (Early Years Foundation Stage profile (EYFS), 2012; Sandwell Primary Care Trust, 2012). The most common tool in use in England (EYFS) lacks sensitivity and specificity for identifying language skills (Seager and Abbott-Smith, 2016). Recently, Snowling has suggested that the best course of action is to monitor progress (Snowling et al., 2011), but this is premised on an understanding of what children's expected trajectories should be [an endeavor that has only recently been addressed in a psychometrically rigorous fashion, see Schmitt et al. (2017)]. 


\section{The Way Forward}

Education staff were positive about a tool to identify children with SLCN. Given the challenges of identifying language and speech difficulties in the classroom context a tool would be a useful resources to profile children's concurrent language learning needs. This would be consistent with other approaches toward profiling needs (Everatt et al., 2008; Roessingh et al., 2015), provided that the limitations in such approaches are addressed (Lindsay and Lewis, 2003; Lindsay et al., 2004). The broader conceptualization of language learning needs should include written language skills that can provide additional leverage in identifying children's language learning needs. For example, poor use of vocabulary in writing may serve as a "red flag" for language learning needs (Cabell et al., 2011).

Why SLTs were reticent about the approach is not clear, though it may reflect the current lack of evidence about screening for speech or language delay (Wallace et al., 2015). The development of a tool which goes beyond the early years to support school staff could be beneficial in providing them with key markers of effective speaking and listening in school-age children and for highlighting pupils who may need further support either in the classroom or by referral to external professionals.

\section{Limitations}

The current study is limited by a number of potential biases. Despite being the largest study of its kind the sample may be biased. For example, only respondents interested in SLCN may have responded, leading to an overestimation of knowledge and understanding. This a particular concern for the Education respondents where knowledge within this group may be overestimated. Responses from participants who did not complete the entire questionnaire further questions the representativeness of the sample. In addition, the results only reflect what respondents reported rather than what actually happens in working practice. Of particular importance is the need to explore further the barriers to effective practice. For example, whilst over $50 \%$ of the SLTs identified "knowing how to support children with SLCN" as a significant barrier it was not clear whether this reflected difficulties of working in schools, the lack of evidence based intervention practices or some other feature or working with children with SLCN. Finally, although both groups of respondents highlighted the need for additional professional development they were not asked about how the

\section{REFERENCES}

Antoniazzi, D., Snow, P., and Dickson-Swift, V. (2010). Teacher identification of children at risk for language impairment in the first year of school. Int. J. Speech Lang. Pathol. 12, 244-252. doi:10.3109/17549500903104447

APA. (2013). Diagnostic and Statistical Manual of Mental Disorders, 5th Edn. Arlington, VA: American Psychiatric Publishing.

Bakopoulou, I., and Dockrell, J. E. (2016). The role of social cognition and prosocial behaviour in relation to the socio-emotional functioning of primary aged children with specific language impairment. Res. Dev. Disabil. 4, 354-370. doi:10.1016/j.ridd.2015.12.013

Baxter, S., Brookes, C., Bianchi, K., Rashid, K., and Hay, F. (2009). Speech and language therapists and teachers working together: exploring the issues. Child Lang. Teach. Ther. 25, 215-234. doi:10.1177/0265659009102984 activities should be delivered, what issues should be addressed nor how the efficacy should be evaluated (Wasik and Hindman, 2014 as an example).

\section{CONCLUSION}

The development of effective services for children with SLCN depends on both mapping provision and examining professionals' understanding so as to develop effective collaborative practice. Using a bespoke questionnaire, we compared the views of experienced SLTs and Education practitioners. The survey demonstrated differences in the understandings of speech and language difficulties but also importantly in ways of removing barriers to effective practice. While there is clearly scope for further training the results also highlight the ways in which the working context influences practice and understandings and the need for bespoke resources to meet the needs in those contexts to meet the children's needs.

\section{ETHICS STATEMENT}

Ethical agreement was provided for the study by the UCL, Institute of Education Research Ethics Committee, which adheres to the British Psychological Society guidelines. Participation was anonymous and voluntary through an online survey. The protocol was approved by the IOE.

\section{AUTHOR CONTRIBUTIONS}

JD and PH conceptualized and conducted the study. DL completed the statistical analyses. AF advised on a completed the classification tree analysis. JD and PH drafted the research paper.

\section{FUNDING}

This project was funded by a UCL/IOE collaboration award.

\section{SUPPLEMENTARY MATERIAL}

The Supplementary Material for this article can be found online at http://journal.frontiersin.org/article/10.3389/feduc.2017.00035/ full\#supplementary-material.

Bishop, D. V. M. (2014). Ten questions about terminology for children with unexplained language problems. Int. J. Lang. Commun. Disord. 49, 381-415. doi:10.1111/1460-6984.12101

Bishop, D. V. M., Snowling, M. J., Thompson, P. A., Greenhalgh, T., and the CATALISE-2 consortium. (2016). CATALISE: a multinational and multidisciplinary delphi consensus study. Identifying language impairments in children. PLoS One 11:e0168066. doi:10.1371/journal.pone.0158753

Bishop, D. V. M., Snowling, M. J., Thompson, P. A., Greenhalgh, T., and the CATALISE-2 consortium. (2017). Phase 2 of CATALISE: a multinational and multidisciplinary Delphi consensus study of problems with language development: terminology. J. Child. Psychol. Psychiatr. doi:10.1111/jcpp.12721

Boscolo, B., Ratner, N. B., and Rescorla, L. (2002). Fluency of school-aged children with a history of specific expressive language impairment: an exploratory study. Am. J. Speech Lang. Pathol. 11, 41-49. doi:10.1044/1058-0360(2002/005) 
Cabell, S. Q., Justice, L. M., Konold, T. R., and McGinty, A. S. (2011). Profiles of emergent literacy skills among preschool children who are at risk for academic difficulties. Early Child. Res. Q. 26, 1-14. doi:10.1016/j.ecresq.2010.05.003

Communication Trust. (2017). Professional Development in Speech Language and Communication. Available at: http://www.thecommunicationtrust.org.uk/ media/526748/1._tct_workforce_development_report_final_online.pdf

Conti-Ramsden, G., Botting, N., and Faragher, B. (2001). Psycholinguistic markers for specific language impairment (SLI). J. Child Psychol. Psychiatry 42, 741-748. doi:10.1111/1469-7610.00770

Conti-Ramsden, G., Durkin, K., Simkin, Z., and Knox, E. (2009). Specific language impairment and school outcomes. I: identifying and explaining variability at the end of compulsory education. Int. J. Lang. Commun. Disord. 44, 15-35. doi:10.1080/13682820801921601

Cowan, R., Donlan, C., Newton, E. J., and Llyod, D. (2005). Number skills and knowledge in children with specific language impairment. J. Educ. Psychol. 97, 732-744. doi:10.1037/0022-0663.97.4.732

Davis, S., Howell, P., and Cook, F. (2002). Sociodynamic relationships between children who stutter and their non-stuttering classmates. J. Child Psychol. Psychiatry 43, 939-947. doi:10.1111/1469-7610.00093

Department for Education. (2015). Special Educational Needs and Disability Code of Practice 0 to 25 Years. Statutory Guidance for Organisations Which Work with and Support Children and Young People Who have Special Educational Needs or Disabilities. Available at: https://www.gov.uk/government/uploads/ system/uploads/attachment_data/file/398815/SEND_Code_of_Practice_ January_2015.pdf

Department of Education and Skills. (2001). Special Educational Needs Code of Practice. London: DfES.

Diepeveen, F. B., Dusseldorp, E., Bol, G. W., Oudesluys-Murphy, A. M., and Verkerk, P. H. (2016). Failure to meet language milestones at two years of age is predictive of specific language impairment. Acta Paediatr. 105, 304-310. doi:10.1111/apa.13271

Dockrell, J., Lindsay, G., Roulstone, S., and Law, J. (2014). Supporting children with speech, language and communication needs: an overview of the results of the Better Communication Research Programme. Int. J. Lang. Commun. Disord. 49, 543-557. doi:10.1111/1460-6984.12089

Dockrell, J. E., and Howell, P. (2015). Identifying the challenges and opportunities to meet the needs of children with speech, language and communication difficulties. Br. J. Spec. Educ. 42, 411-428. doi:10.1111/1467-8578.12115

Dockrell, J.E., and Lindsay, G. (2001). Children with specific speech and language difficulties - the teachers' perspective. Oxford Rev. Educ. 27, 369-394. doi:10.1080/713688574

Dockrell, J. E., and Marshall, C. R. (2015). Measurement issues: assessing language skills in young children. Child Adolesc. Ment. Health 20, 116-125. doi:10.1111/ camh. 12072

Dockrell, J. E., Lindsay, G., and Connelly, V. (2009). The impact of specific language impairment on adolescents' written text. Except. Child. 75, 427-446. doi:10.1177/001440290907500403

Dockrell, J. E., Lindsay, G., and Palikara, O. (2011). Explaining the academic achievement at school leaving for pupils with a history of language impairment: previous academic achievement and literacy skills. Child Lang. Teach. Ther. 27, 223-237. doi:10.1177/0265659011398671

Donlan, C., Cowan, R., Newton, E. J., and Lloyd, D. (2007). The role of language in mathematical development: evidence from children with specific language impairments. Cognition 103, 23-33. doi:10.1016/j.cognition.2006.02.007

Durkin, K., Simkin, Z., Knox, E., and Conti-Ramsden, G. (2009). Specific language impairment and school outcomes. II: educational context, student satisfaction, and post-compulsory progress. Int. J. Lang. Commun. Disord. 44, 36-55. doi:10.1080/13682820801921510

Early Years Foundation Stage profile (EYFS). (2012). Development Matters in the Early Years Foundation Stage. London: Early Education.

Ebbels, S. H., McCartney, E., Slonims, V., Dockrell, J. E., and Norbury, C. (2017). Evidence based pathways to intervention for children with language disorders. PeerJ Preprints 5, e2951v1. doi:10.7287/peerj.preprints.2951v1

Everatt, J., Weeks, S., and Brooks, P. (2008). Profiles of strengths and weaknesses in dyslexia and other learning difficulties. Dyslexia 14, 16-41. doi:10.1002/dys.342

Glover, A., McCormack, J., and Smith-Tamaray, M. (2015). Collaboration between teachers and speech and language therapists: services for primary school children with speech, language and communication needs. Child Lang. Teach. Ther. 31, 363-382. doi:10.1177/0265659015603779
Gracia, M., Vega, F., and Galvan-Bovaira, M. J. (2015). Developing and testing EVALOE: a tool for assessing spoken language teaching and learning in the classroom. Child Lang. Teach. Ther. 31, 287-304. doi:10.1177/0265659015593608

Hambly, H., Wren, Y., McLeod, S., and Roulstone, S. (2013). The influence of bilingualism on speech production: a systematic review. Int. J. Lang. Commun. Disord. 48, 1-24. doi:10.1111/j.1460-6984.2012.00178.x

Hartas, D. (2004). Teacher and speech language therapists collaboration: being equal and achieving a common goal. Child Lang. Teach. Ther. 20, 21. doi:10.1191/0265659004ct262oa

Houdrow, A., Larson, K., Olson, M., Newacheck, P., and Halfon, N. (2014). Changing trends in childhood disability. Paediatrics 134, 530-538. doi:10.1542/ peds.2014-0594

Howell, P., Tang, K., Tuomainen, O., Chan, S. K., Beltran, K., Mirawdeli, A., et al. (2016). Identification of fluency and word-finding difficulty in samples of children with diverse language backgrounds. Int. J. Lang. Commun. Disord. doi:10.1111/1460-6984.12305

Korpilahti, P., Kaljonen, A., and Jansson-Verkasalo, E. (2016). Identification of biological and environmental risk factors for language delay: the Let's Talk STEPS study. Infant Behav. Dev. 42, 27-35. doi:10.1016/j.infbeh.2015. 08.008

Law, J., Boyle, J., Harris, F., Harkness, A., and Nye, C. (2000). Prevalence and natural history of primary speech and language delay: findings from a systematic review of the literature. Int. J. Lang. Commun. Disord. 35, 165-188. doi:10.1080/136828200247133

Leitao, S., and Fletcher, J. (2004). Literacy outcomes for students with speech impairment: long-term follow-up. Int. J. Lang. Commun. Disord. 39, 245-256. doi:10.1080/13682820310001619478

Lindsay, G., and Dockrell, J. E. (2000). The behaviour and self-esteem of children with specific speech and language difficulties. Br. J. Educ. Psychol. 70, 583-601. doi:10.1348/000709900158317

Lindsay, G., Dockrell, J. E., and Palikara, O. (2010a). Self-esteem of adolescents with specific language impairment as they move from compulsory education. Int. J. Lang. Commun. Disord. 45, 561-571. doi:10.3109/13682820903324910

Lindsay, G., Dockrell, J. E., Desforges, M., Law, J., and Peacey, N. (2010b). Meeting the needs of children and young people with speech, language and communication difficulties. Int. J. Lang. Commun. Disord. 45, 448-460. doi:10.3109/ 13682820903165693

Lindsay, G., and Lewis, A. (2003). An evaluation of the use of accredited baseline assessment schemes in England. Br. Educ. Res. J. 29, 149-167. doi:10.1080/ 0141192032000060902

Lindsay, G., Martineau, E., and Lewis, A. (2004). The consistency of baseline assessment schemes as measures of early literacy. J. Res. Read. 27, 118-131. doi:10.1111/j.1467-9817.2004.00220.x

Lindsay, G., Soloff, N., Law, J., Band, S., Peacey, N., Gascoigne, M., et al. (2002). Speech and language therapy services to education in England and Wales. Int. J. Lang. Commun. Disord. 37, 273-288. doi:10.1080/13682820210137204

Mackie, C. J., Dockrell, J., and Lindsay, G. (2013). An evaluation of the written texts of children with SLI: the contributions of oral language, reading and phonological short-term memory. Read. Writ. 26, 865-888. doi:10.1007/ s11145-012-9396-1

Marshall, J., and Lewis, E. (2014). 'It's the way you talk to them.' The child's environment: early years practitioners' perceptions of its influence on speech and language development, its assessment and environment targeted interventions. Child Lang. Teach. Ther. 30, 337-352. doi:10.1177/0265659013516331

Marshall, J., Ralph, S., and Palmer, S. (2002). 'I wasn't trained to work with them': mainstream teachers' attitudes to children with speech and language difficulties. Int. J. Inclusive Educ. 6, 199-215. doi:10.1080/13603110110067208

Mashburn, A. J., and Myers, S. S. (2010). Advancing research on children with speech-language impairment: an introduction to the early childhood longitudinal study-Kindergarten Cohort. Lang. Speech Hear. Serv. Sch. 41, 61-69. doi:10.1044/0161-1461(2009/08-0037)

McCartney, E. (1999). Barriers to collaboration: an analysis of systemic barriers to collaboration between teachers and speech and language therapists. Int. J. Lang. Commun. Disord. 34, 431-440. doi:10.1080/136828299247379

McIntosh, K., Mercer, S. H., Hume, A. E., Frank, J. L., Turri, M. G., and Mathews, S. (2013). Factors related to sustained implementation of schoolwide positive behavior support. Except. Child. 79, 293-311.

McLeod, S., and McKinnon, D. H. (2007). Prevalence of communication disorders compared with other learning needs in 14500 primary and secondary 
school students. Int. J. Lang. Commun. Disord. 42, 37-59. doi:10.1080/ 136828206001173262

Mroz, M., and Hall, E. (2003). Not yet identified: the knowledge, skills, and training needs of early years professionals in relation to children's speech and language development. Early Years 23, 13. doi:10.1080/09575140303109

Nation, K., Clarke, P., Marshall, C. M., and Durand, M. (2004). Hidden language impairments in children: parallels between poor reading comprehension and specific language impairment? J. Speech Lang. Hear. Res. 47, 199-211. doi:10.1044/1092-4388(2004/017)

National Childcare Accreditation Council. (2010). Putting Children First, 35, 9-11.

Norbury, C. F., Gooch, D., Baird, G., Charman, T., Simonoff, E., and Pickles, A. (2016). Younger children experience lower levels of language competence and academic progress in the first year of school: evidence from a population study. J. Child Psychol. Psychiatry 57, 65-73. doi:10.1111/jcpp.12431

Pawlowska, M. (2014). Evaluation of three proposed markers for language impairment in English: a meta-analysis of diagnostic accuracy studies. J. Speech Lang. Hear. Res. 57, 2261-2273. doi:10.1044/2014_jslhr-1-13-0189

Prelock, P. A. (2000). Prologue-multiple perspectives for determining the roles of speech-language pathologists in inclusionary classrooms. Lang. Speech Hear. Serv. Sch. 31, 213-218. doi:10.1044/0161-1461.3103.213

Pring, T. (2016). Inequalities in the provision of paediatric speech and language therapy services across London boroughs. Int. J. Lang. Commun. Disord. 51, 442-446. doi:10.1111/1460-6984.12221

Pring, T., Flood, E., Dodd, B., and Joffe, V. (2012). The working practices and clinical experiences of paediatric speech and language therapists: a national UK survey. Int. J. Lang. Commun. Disord. 47, 696-708. doi:10.1111/j.1460-6984.2012. 00177.x

Public Health England. (2016). The Mental Health of Children and Young People in England. Available at: https://www.gov.uk/government/uploads/ system/uploads/attachment_data/file/575632/Mental_health_of_children_in_ England.pdf

R Core Team. (2017). R: A Language and Environment for Statistical Computing. Vienna, Austria: R Foundation for Statistical Computing.

Reilly, S., Onslow, M., Packman, A., Wake, M., Bavin, E. L., Prior, M., et al. (2009). Predicting stuttering onset by the age of 3 years: a prospective, community cohort study. Pediatrics 123, 270-277. doi:10.1542/peds.2007-3219

Reilly, S., Tomblin, B., Law, J., McKean, C., Mensah, F. K., Morgan, A., et al. (2014). Specific language impairment: a convenient label for whom? Int. J. Lang. Commun. Disord. 49, 416-451. doi:10.1111/1460-6984.12102

Reilly, S., Wake, M., Ukoumunne, O. C., Bavin, E., Prior, M., Cini, E., et al. (2010). Predicting language outcomes at 4 years of age: findings from early language in Victoria Study. Pediatrics 126, E1530-E1537. doi:10.1542/peds. 2010-0254

Riley, G. (2009). The Stuttering Severity Instrument for Adults and Children (SSI-4), 4th Edn. Austin, TX: PRO-ED.

Roessingh, H., Elgie, S., and Kover, P. (2015). Using lexical profiling tools to investigate children's written vocabulary in grade 3: an exploratory study. Lang. Assess. Q. 12, 67-86. doi:10.1080/15434303.2014.936603

Sadler, J. (2005). Knowledge, attitudes and beliefs of the mainstream teachers of children with a preschool diagnosis of speech/language impairment. Child Lang. Teach. Ther. 21, 16. doi:10.1191/0265659005ct286oa

Sandwell Primary Care Trust. (2012). Wellcomm: A Speech and Language Toolkit for the Early Years. UK: Granada/NFER Nelson.

Schmitt, M. B., Logan, J. A. R., Tambyraja, S. R., Farquharson, K., and Justice, L. (2017). Establishing language benchmarks for children with typically developing language and children with language impairment. J. Speech. Lang. Hear. Res. 60, 364-378. doi:10.1044/2016_JSLHR-L-15-0273

Schwab, J. F., and Lew-Williams, C. (2016). Language learning, socioeconomic status, and child-directed speech. Wiley Interdiscip. Rev. Cogn. Sci. 7, 264-275. doi:10.1002/wcs.1393
Seager, E., and Abbot-Smith, K. (2016). Can early years professionals determine which preschoolers have comprehension delays? A comparison of two screening tools. Child Lang. Teach. Ther. doi:10.1177/0265659016650977

Skahan, S. M., Watson, M., and Lof, G. L. (2007). Speech-language pathologists' assessment practices for children with suspected speech sound disorders: results of a national survey. Am. J. Speech. Lang. Pathol. 1, 246-259. doi:10.1044/1058-0360(2007/029)

Snow, C. E. (2014). Input to interaction to instruction: three key shifts in the history of child language research. J. Child Lang. 41, 117-123. doi:10.1017/ s0305000914000294

Snowling, M. J., and Hayiou-Thomas, M. E. (2006). The dyslexia spectrumcontinuities between reading, speech, and language impairments. Top. Lang. Disord. 26, 110-126. doi:10.1097/00011363-200604000-00004

Snowling, M. J., Hulme, C., Bailey, A. M., Stothard, S. E., and Lindsay, G. (2011). Better Communication Research Project: Language and Literacy Attainment of Pupils during Early Years and through KS2: Does Teacher Assessment at Five Provide a Valid Measure of Children's Current and Future Educational Attainments? London: DfE.

St Clair, M. C., Pickles, A., Durkin, K., and Conti-Ramsden, G. (2011). A longitudinal study of behavioral, emotional and social difficulties in individuals with a history of specific language impairment (SLI). J. Commun. Disord. 44, 186-199. doi:10.1016/j.jcomdis.2010.09.004

Strand, S., and Lindsay, G. (2009). Evidence of ethnic disproportionality in special education in an english population. J. Spec. Educ. 43, 174-190. doi:10.1177/0022466908320461

Therneau, T., Atkinson, B., and Ripley, B. (2015). rpart: Recursive Partitioning and Regression Trees. Available at: https://cran.r-project.org/web/packages/rpart/ index.html

Tudor, H., Davis, S., Brewin, C., and Howell, P. (2013). Recurrent involuntary imagery in people who stutter and people who do not stutter. J. Fluency Disord. 38, 247-259. doi:10.1016/j.jfludis.2013.06.003

Vanormelingen, L., and Gillis, S. (2016). The influence of socio-economic status on mothers' volubility and responsiveness in a monolingual Dutch-speaking sample. First Lang. 36, 140-156. doi:10.1177/0142723716639502

Wallace, I. F., Berkman, N. D., Watson, L. R., Coyne-Beasley, T., Wood, C. T., Cullen, K., et al. (2015). Screening for speech and language delay in children 5 years old and younger: a systematic review. Pediatrics 136, E448-E462. doi:10.1542/peds.2014-3889

Wasik, B. A., and Hindman, A. H. (2014). Understanding the active ingredients in an effective preschool vocabulary intervention: an exploratory study of teacher and child talk during book reading. Early Educ. Dev. 25, 1035-1056. doi:10.1080/ 10409289.2014.896064

Wilson, L., McNeill, B., and Gillon, G. T. (2016). A comparison of inter-professional education programs in preparing prospective teachers and speech and language pathologists for collaborative language-literacy instruction. Read. Writ. 29, 1179-1201. doi:10.1007/s11145-016-9631-2

Wright, T. S., and Neuman, S. B. (2014). Paucity and disparity in kindergarten oral vocabulary instruction. J. Literacy Res. 46, 330-357. doi:10.1177/10862 $96 \times 14551474$

Conflict of Interest Statement: The authors declare that the research was conducted in the absence of any commercial or financial relationships that could be construed as a potential conflict of interest.

Copyright (C) 2017 Dockrell, Howell, Leung and Fugard. This is an open-access article distributed under the terms of the Creative Commons Attribution License (CC BY). The use, distribution or reproduction in other forums is permitted, provided the original author(s) or licensor are credited and that the original publication in this journal is cited, in accordance with accepted academic practice. No use, distribution or reproduction is permitted which does not comply with these terms. 